\title{
C TO T TRANSITION AT THE FIRST NUCLEOTIDE OF CODON 63 OF THE $\beta$-GLOBIN GENE CORRESPONDING TO HEMOGLOBIN M-SASKATOON IN AN INDONESIAN BOY
}

\author{
Purnomo Suryantoro, ${ }^{1,2}$ Yasuhiro Takeshima, ${ }^{1}$ Alimsardjono Haryanto, ${ }^{1}$ \\ and Masafumi MATSUO ${ }^{1, *}$ \\ ${ }^{1}$ Division of Genetics, International Center for Medical Research, \\ Kobe University School of Medicine, \\ 7-5-1 Kusunokicho, Chuo-ku, Kobe 650, Japan \\ ${ }^{2}$ Department of Child Health, Gadya Mada University Faculty of Medicine, \\ Yogyakarta, Indonesia
}

\begin{abstract}
Summary Hemoglobin ( $\mathrm{Hb}$ ) M-Saskatoon, a $\beta$ variant of methemoglobin, is characterized by mild hemolysis. It is caused by the substitution of a histidine by a tyrosine at the 63rd amino acid residue of the $\beta$-globin chain. Amplification and sequence analysis of genomic $\beta$-globin DNA from an Indonesian boy diagnosed as having the more severe disease thalassemia demonstrated the presence of a $\mathrm{C}$ to $\mathrm{T}$ transition at nucleotide 473 in one of the two $\beta$-blogin genes resulting in a histidine to tyrosine substitution at 63 rd residue. This amino acid change matched with that reported in $\mathrm{Hb} \mathrm{M}-\mathrm{Saskatoon}$. This nucleotide change abolished a recognition site for the restriction endonuclease NlaIII. NlaIII digestion of the corresponding $\beta$-globin DNA amplified from the patient's parents indicated that the mutation was inherited through from his mother. This result shows that the world-wide distribution of $\mathrm{Hb}$ M-Saskatoon extends to Indonesia, where it was not previously identified. Possible causes of the unusually severe symptoms observed in the case are discussed.
\end{abstract}

Key Words hemoglobin M, hemoglobin M-Saskatoon, $\beta$-globin, thalassemia

\section{INTRODUCTION}

Methemoglobins ( $\mathrm{Hb} \mathrm{Ms}$ ) are a group of mutant hemoglobins (Hbs) which have amino acid substitutions in the heme pocket that directly affects the hemeglobin bond. Amino acid analysis of $\mathrm{Hb} \mathrm{Ms}$ disclosed substitutions of histidine

Received December 19, 1994; Revised version accepted March 1, 1995.

* To whom correspondence should be addressed. 
residues in either the $\alpha$ or $\beta$ chains of globin. The abnormal chains are maintained in the ferric (methemoglobin) form and cannot undergo reversible oxygenation. Patients with $\alpha$-chain hemoglobin $M$ show severe clinical symptoms such as cyanosis from birth, but $\beta$-chain hemoglobin $\mathrm{M}$ induces only mild clinical symptoms. $\mathrm{Hb}$ M Saskatoon is one of the $\beta$-chain $\mathrm{Hb}$ Ms. It shows a dominant inheritance pattern and is characterized by the substitution of a histidine by a tyrosine at the 63 rd residue (Bunn and Forget, 1986).

Several lines of evidence indicate that $\beta$-globin of $\mathrm{Hb}$ M Saskatoon is slightly unstable. $\mathrm{Hb} \mathrm{M}$-Saskatoon produces only mild compensated hemolysis (Baine et al., 1980), which is sometimes markedly accelerated by exposure to heat or the administration of an oxidant drug (Bunn and Forget, 1986). There has been no report of a $\mathrm{Hb} \mathrm{M}$-Saskatoon case showing severe anemia such as $\beta$-thalassemia.

$\mathrm{Hb}$ M-Saskatoon has been found in Germany, Canada, Britain, the United States, France, Denmark, Norway, Poland, Italy, South Africa, Japan, the Soviet Union (Bunn and Forget, 1986), and Algeria (Arbane-Dahmane et al., 1985). The various exotic names that have been applied to $\mathrm{Hb} \mathrm{M}$-Saskatoon provide further testimony to the world-wide distribution of these variants. However, no case has been reported from South East Asia where many other kinds of mutations of the $\beta$-globin gene have been reported (Fucharoen et al., 1989; Lie-Injo et al., 1989).

In the past, $\mathrm{Hb} \mathrm{M}$-Saskatoon has been identified by analyzing the amino acid sequence of $\beta$-globin (Bunn and Forget, 1986). Recent advances in molecular biology make it possible to determine mutations at DNA sequence level. Until now there has been no report describing the nucleotide changes in $\mathrm{Hb} \mathrm{M}$-Saskatoon, although a $\mathrm{C}$ to $\mathrm{T}$ transition must have occurred at $\mathrm{nt} .473$ in order to cause the observed amino acid substitution at the 63rd residue. In this report we demonstrated that codon 63 was changed from CAT to TAT in an Indonesian patient showing signs of thalassemia, and that NlaIII digestion of PCR amplified exon 2 region from genomic $\beta$-globin DNA can be used as a simple method to detect this mutation.

\section{CASE AND METHODS}

Case. A 10-year-old Indonesian male was admitted to Dr. Sardjito Hospital, Yogyakarta, Indonesia, because of paleness. He was born to Indonesian parents and had no siblings. Although his father and mother had been in healthy condition, they showed mild anemia (11.8 and $10.2 \mathrm{~g} / \mathrm{dl}$, respectively) and high fetal hemoglobin $(6.8$ and $7.8 \%$, respectively: control, $<0.4 \%)$. No other abnormal peak was pointed out on their electrophoretic pattern of hemoglobin. No definitive clinical diagnosis has been established in his parents.

His mother noticed his paleness when he was 3 months old. At the age of 4 , abdominal distention was noticed and an abdominal tumor was diagnosed by a doctor. At 4.5 year old, the abdominal tumor was identified as a distended spleen and splenectomy was performed. After the operation he was in good condition 
and had no significant clinical abnormalities. However, at the age of 8 he was found to be still anemic $(10.3 \mathrm{~g} / \mathrm{dl})$; electrophoretic analysis of hemoglobin showed a high percentage of fetal hemoglobin $(8.2 \%$ ) but no other abnormality in electrophoretic pattern was pointed out. He was clinically diagnosed as having thalassemia major.

After admission to hospital, he was examined for his paleness. Physical examination showed no remarkable finding except paleness. History taking disclosed no particular incident before his admission. Only blood examination disclosed severe anemia $(6.2 \mathrm{~g} / \mathrm{dl})$. In spite of intensive care he died because of unexpected cardiac arrest. Blood obtained before blood transfusion was subjected to a search for a mutation in the $\beta$-globin gene.

Methods. DNA was extracted from blood cells by standard phenol/chloroform extraction methods and used as a template for polymerase chain reaction (PCR) amplification. The $\beta$-globin gene was amplified as three separate fragments (fragment I, II, and III) by using three sets of primers (Table 1). Each of three fragments covers one entire exon and its flanking introns. PCR was carried out as described previously (Varawalla et al., 1991). The amplified DNA fragment was separated by electrophoresis on a $3 \%$ agarose gel and photographed after ethidium bromide staining.

The amplified DNA was directly subcloned into pT7Blue T-vector (Novagen, Madison, WI). The sequences of inserted DNA from 9-10 clones of each amplified DNA were determined using an automatic DNA sequencer (model 373A: Applied Biosystems, Foster City, CA) with the Taq dye primer cycle sequencing kit (Applied Biosystems, Foster City, CA).

In order to study the inheritance of the mutation and to determine its incidence among thalassemia patients, the amplified product containing exon 2 (fragment II in Table 1) was digested with NlaIII according to the method suggested by the supplier (Toyobo, Osaka) and the digested fragments were electrophoresed in a $3 \%$ agarose gel.

\section{RESULTS}

Since the patient was clinically diagnosed as thalassemia major, we tried to identify mutations in the $\beta$-globin gene. The $\beta$-globin gene were amplified as three

Table 1. Primer sequences used to amplify three fragments of the $\beta$-globin gene.

\begin{tabular}{clc}
\hline Fragment & \multicolumn{1}{c}{ Sequence 5'-3 } & Complementary site ${ }^{2}$ \\
\hline \multirow{2}{*}{ I } & ACCTCACCCTGTGGAGCCAC & -5 to 14 \\
& GAGAGAGTCAGTGCCTATCA & 346 to 327 \\
II & AGAAACTGGGCATGTGGAGA & 286 to 305 \\
& CCCCTTCCTATGACATGAACTTAA & 670 to 647 \\
III & ATTCTGAGTCCAAGCTAGGC & 1386 to 1405 \\
& TGCACTGACCTCCCACATTC & 1771 to 1752 \\
\hline
\end{tabular}

a Numbering of the $\beta$-globin sequence is according to Lawn et al. (1980). 
separate regions. Electrophoresis on agarose gels revealed the three amplified products as single DNA bands which comigrated with the corresponding products amplified from the genomic DNA of a normal individual. To determine whether a point mutation was present in the patient's $\beta$-globin genes we sequenced all three amplified fragments as described in the methods section. The nucleotide sequences of amplified DNAs covering exon 1 and its flanking introns (fragment I) or exon 3 and its flanking introns (fragment III) were identical to those of the wild-type gene in all clones studied. In particular, two types of DNA clone were obtained by subcloning the amplified exon 2 encompassing DNA (fragment II). The sequence of one of them was identical to that of wild type exon 2 region (Fig. 1 lower panel). The other type of clone had a single nucleotide change, from $\mathrm{C}$ to $\mathrm{T}$, at position 473 (Fig. 1 upper panel). The mutated nucleotide corresponded to the first base of codon 63 of $\beta$-globin; the codon is changed from CAT to TAT, resulting in a histidine to tyrosine substitution. This amino acid substitution has been reported as $\mathrm{Hb} \mathrm{M}$-Saskatoon. Thus, we diagnosed the case as $\mathrm{Hb}$ M-Saskatoon at the molecular level.

As the $\mathrm{C}$ to $\mathrm{T}$ transition was located in the sequence CATG recognized by the restriction endonuclease NlaIII, the DNA fragment harboring the mutation should

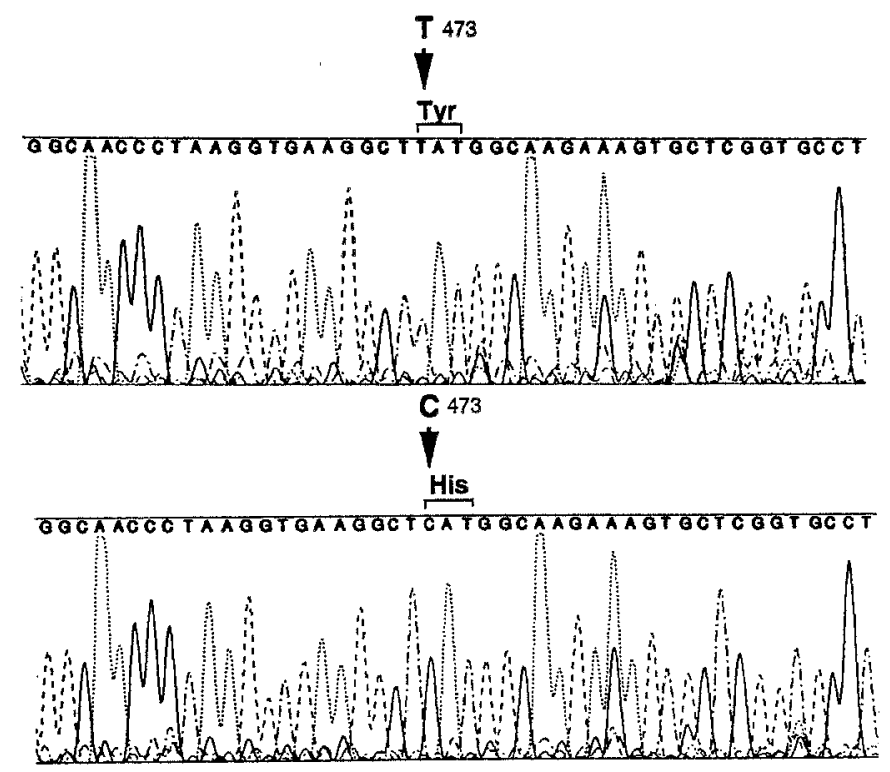

Fig. 1. Nucleotide sequence of part of the $\beta$-globin gene. Only the nucleotide sequences around the site of point mutation of exon 2 were described. In the nucleotide sequence of the patient's DNA nucleotide T (nt. 473) at the first nucleotide of codon 63 (bottom) was replaced by $\mathrm{C}$ nucleotide (top). Bracket indicates 63rd codon. The NlaIII restriction enzyme recognition site (CATG) was absent from the patient's sequence. The numbering is according to the $\beta$-globin sequence (Lawn et al., 1980). 


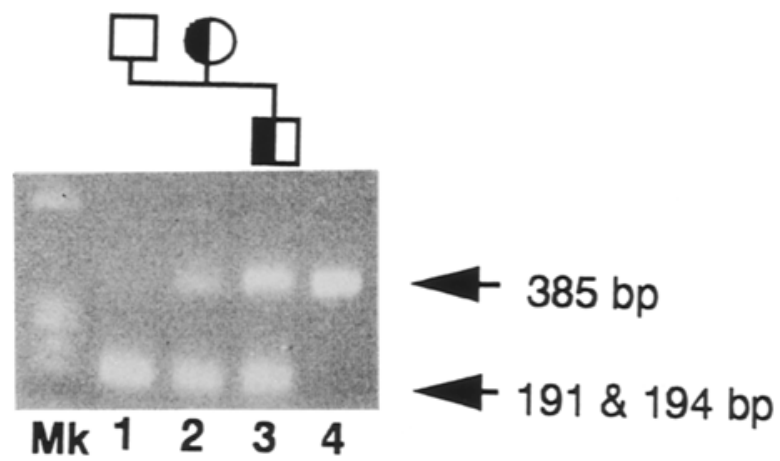

Fig. 2. NlaIII digestion of PCR-amplified genomic DNA. A gemonic DNA fragment encompassing exon 2 of the $\beta$-globin gene (fragment II) was amplified, digested with NlaIIT, and subjected to electrophoresis. The allele with a point mutation at $\mathrm{T}$ to $\mathrm{C}$ remained intact as a $385 \mathrm{bp}$ fragment which corresponds to the undigested product (lane 4), but digestion of the normal DNA yielded one visible fragment consisting of 191 and $194 \mathrm{bp}$ fragments (lane 2). Top, pedigree with squares representing males and circles representing females. The affected individual is represented by a filled symbol and the carrier state is represented by half-filled symbol. The size marker is a size ladder HincII digested $\varnothing \times 174$ phage DNA (Toyobo, Osaka).

not be cleaved by this enzyme. The normal amplified product was indeed digested completely to produce two fragments (191 and $194 \mathrm{bp}$ ) which comigrated upon electrophoresis (Fig. 2 lane 1). In contrast, two bands were visualized on the agarose gel when the digested product of the patient was applied (Fig. 2 lane 3). The larger band was identified as uncleaved DNA (Fig. 2 lane 4), the other band representing the mixed 191 and $194 \mathrm{bp}$ bands found in the digested DNA from the normal individual (Fig. 2 lane 1). These results confirmed that the patient was heterozygous for the mutation.

To determine the inheritance pattern of the mutation, amplified products from the parents were also subjected to NlaIII restriction enzyme digestion. Although amplified exon 2 encompassing region (fragment II) from the father was completely digested by the enzyme, fragment II from his mother produced a mixture of two clearly resolved bands identical to those obtained with fragment II from the patient. This result showed his mother carries the same mutation and thus that the $\mathrm{Hb} \mathrm{M}$ Saskatoon allele was inherited from his mother.

To determine the incidence of the mutation among Indonesian thalassemia patients, amplified fragment II from 50 cases was digested with NlaIII. In all 50 cases, the amplified DNA fragment was correctly and completely cleaved by the restriction enzyme, indicating that the mutation is not common among thalassemia patients. 


\section{DISCUSSION}

$\mathrm{Hb} \mathrm{M}$-Saskatoon results from the substitution of the $63 \mathrm{rd}$ residue of $\beta$-globin chain, histidine, by tyrosine. The only point mutation which can cause this amino acid change is a $\mathrm{C}$ to $\mathrm{T}$ transition at the first nucleotide of the codon, as shown to be the case here.

Our result confirmed that $\mathrm{Hb}$ M-Saskatoon is also present in Indonesia, where $\beta$-thalassemia is common. In malaria endemic areas as Indonesia, three hemoglobinopathies including $\alpha$ - and $\beta$-thalassemias and sickle cell anemia are very common genetic diseases since they confer resistance to malarial infection. In contrast to these hemoglobinopathies, the hemoglobinopathy of $\mathrm{Hb}$ M-Saskatoon has been reported to be rare in black people, although a case has been reported in Africa (Arbane-Dahmane et al., 1985). In the present study we failed to identify the same mutation in group of 50 Indonesia patients with thalassemia. Thus, the mutation seems to be rare even though mutations in the $\beta$-globin gene are common among Indonesians.

If we accept that all $\mathrm{Hb} \mathrm{M}$-Saskatoon cases are due to a single ancestral mutation, then it must have spread throughout the world by population migration. Another possibility is that an unknown factor predisposing the same mutation may be present around the mutation site in the $\beta$-globin gene. $\mathrm{C}$ to $\mathrm{T}$ transitions such as that found in $\mathrm{Hb} \mathrm{M}$-Saskatoon are the commonest point mutations identified in human genes (Labuda and Striker, 1989).

In the present case, we could not identify any mutation other than $\mathrm{Mb} \mathrm{H}$ Saskatoon in the analyzed regions of the $\beta$-globin gene including both exon and intron sequences (Table 1). Thus the thalassemia diagnosis could not be confirmed at the molecular level. However, the patient's symptoms were clearly those of $\beta$-thalassemia rather than of $\mathrm{Hb}$ M-Saskatoon. We consider that the severe symptoms might be explained in three ways. First, both parents have high levels of blood fetal hemoglobin, and are therefore likely to be thalassemia carriers. Thus, the patient may have been a compound heterozygote for thalassemia, a situation which is not uncommon among South-East Asians. However, we have so-far failed to identify any nucleotide changes (other than the $\mathrm{C}$ to $\mathrm{T}$ transition in exon 2 ) in the sequenced segments of the child's $\beta$-globin gene, which would argue against this idea.

The second possibility is that the case inherited the $\mathrm{Hb}$ M-Saskatoon trait from his mother and the $\beta$-thalassemia trait from his father. The $\beta$ chain bearing the tyrosine substitution is reportedly synthesized at the normal rate, but is more likely to be degraded than normal $\beta$ chains (Baine et al., 1980). This may induce an imbalance of the levels of $\alpha$ and $\beta$ chains in red blood cells, as observed in thalassemia. Thus, a patient who is compound-heterozygous for both Hb M-Saskatoon and $\beta$-thalassemia may exhibit severe anemia like that shown by patients with $\beta$ thalassemia. Since, as mentioned above, we have not yet identified the mutation 
responsible for the thalassemia heterozygosity in this case, this supposition must be tested by further studies.

The third proposed explanation for the severe clinical signs is that they are indeed due solely to $\mathrm{Hb} \mathrm{M}$-Saskatoon. In one case of $\mathrm{Hb}$ M-Saskatoon, signs of mild hemolysis, anemia, splenomegaly, reticulocytosis, and hyperbilirubinemia were reported (Shibata et al., 1967), although all of these signs are fully compatible with $\beta$-thalassemia. Thus, the index case be another unusual case of $\mathrm{Hb} \mathrm{M}$-Saskatoon, but why did he develop severe anemia at the last stage? The answer might be that he was exposed to an unknown oxidizing agent which triggered the severe hemolytic crisis as described in some $\mathrm{Hb} \mathrm{M}$ cases (Bunn and Forget, 1986). However, this hypothesis seems incompatible with the fact that the mother carrying the same mutation did not show signs of anemia during the same period, even though she would probably have been exposed to the same conditions as her son. One way to determine the cause of the severe anemia and to discover its genetic basis will be to study the case histories of other patients with $\mathrm{Hb}$ M-Saskatoon. NlaIII digestion of amplified $\beta$-globin exon 2 region provides a simple method for the molecular diagnosis of this disease, and could prove particularly useful in such a study.

Acknowledgments This work was supported by grants from the Ministry of Education, Science and Culture of Japan and the Nakayama Foundation for Human Science. P.S. is a researcher under the Ronpaku (Dissertation Ph.D.) program supported by the Japan Society for Promotion of Science (JSPS).

\section{REFERENCES}

Arbane-Dahmane M, Rouabhi F, Hocine M, Benabadji M, Redad M, Blouquit Y, Arous N, Delanoe-Garin J, Riou J, Lacombe C, Rosa J, Galactros F (1985): Hemoglobin in Saskatoon ( $\alpha 2 \beta 2$ 63(E7) His-Tyr) in an Algerian family. Hemoglobin 9: 509-511

Baine RM, Wright JM, Johnson MH, Cadena CL (1980): Biosynthetic evidence for instability of $\mathrm{Hb}$ M Saskatoon. Hemoglobin 4: 201-207

Bunn HF, Forget BG (1986): Hemoglobin: molecular, genetic and clinical aspects. W.B. Saunders Company, Philadelphia

Fucharoen S, Fucharoen G, Sriroongrueng W, Laosombat V, Jetsrisuparb A, Prasatkaew S, Tanphaichitr V, Suvatte V, Tuchinda S, Fukumaki Y (1989): Molecular basis of $\beta$-thalassemia in Thailand: analysis of $\beta$-thalassemia mutations using the polymerase chain reaction. Hum Genet 84: $41-46$

Labuda D, Striker G (1989): Sequence conservation in Alu evolution. Nucleic Acids Res 17: 2477 2491

Lawn R, Efstratiadis A, O'Connell C, Maniatis T (1980): The nucleotide sequence of the human $\beta$-globin gene. Cell 21: 647-651

Lie-Injo L, Cai S-P, Wahidijat I, Moeslichan S, Lim M, Evangelista L, Doherty M, Kan Y (1989): $\beta$-Thalassemia mutations in Indonesia and their linkage to $\beta$-haplotypes. Am J Hum Genet 45 : 971-975

Shibata S, Miyaji T, Iuchi I, Ohba Y, Yamamoto K (1967): Hemoglobin M's of Japanese. Bull Yamaguchi Med Sch 14: 141-147

Varawalla N, Old J, Sarkar R, Venkatesan R, Weatherall D (1991): The spectrum of $\beta$-thalassemia mutations of the Indian subcontinent: the basis for prenatal diagnosis. Br J Haematol 78: 242-247 